\title{
Vibration and Long-Term Performance Analysis of Pile-Plank-Supported Low Subgrade of Ballastless Track under Excitation Loads
}

\author{
Junjie Huang, ${ }^{1,2}$ Qian Su, ${ }^{1,2}$ Ting Liu, ${ }^{1}$ and Xun Wang ${ }^{1}$ \\ ${ }^{1}$ School of Civil Engineering, Southwest Jiaotong University, Chengdu 610031, China \\ ${ }^{2}$ MOE Key Laboratory of High-Speed Railway Engineering, Southwest Jiaotong University, Chengdu 610031, China
}

Correspondence should be addressed to Qian Su; suqian@126.com

Received 20 November 2014; Revised 19 January 2015; Accepted 24 March 2015

Academic Editor: Luigi Garibaldi

Copyright (C) 2015 Junjie Huang et al. This is an open access article distributed under the Creative Commons Attribution License, which permits unrestricted use, distribution, and reproduction in any medium, provided the original work is properly cited.

\begin{abstract}
Pile-plank structures are widely applied for high-speed railway built in soft ground in China. It can be used as a reinforcement to improve the behavior of subgrade by providing vertical confinement to increase their stiffness and strength and reduce the subgrade settlement of ballastless track. However, the use of pile-board structure for soft ground reinforcement of high-speed railway is hindered by the existing gap between applications and theories. To verify vibration characteristics and long-term performance of pile-plank-supported low subgrade of ballastless track and the benefit of pile-board structure, an experimental study was conducted on low subgrade of pile-board under excitation loads using both in situ frequency sweeping and cyclic loading experiments. The frequency sweeping experimental results show that the pile-plank-supported low subgrade has smooth stiffness along the longitudinal subgrade and can effectively control the progressive effects of train speed on dynamic stiffness of the subgrade, which ensures driving safety and comfort. The cycle loading experimental results show that the pile-plank-supported low subgrade has favorable long-term dynamic stability, and its dynamic response is uniform along the longitudinal subgrade.
\end{abstract}

\section{Introduction}

With the increasing speed of trains, there is a requirement for more analyses of train-induced vibrations. A number of new numerical or semianalytical methods and experimental approaches for the analysis of vibrations induced by highspeed trains have been developed in recent years. Thach et al. [1] study vibration behaviors of this embankment system under high-speed train passage which are investigated through three-dimensional finite element simulation. Li et al. [2] study dynamic responses of frozen embankment under train load. And the railway engineering community has researched vibrations of the ground and structures (e.g., subgrade structures and tracks) induced by high-speed train (HST) passage on ballasted and ballastless tracks. These studies have included some analysis of the track subgrade vibrations and the effects of vibration on structures under the track subgrade.
Recently, Su and Cai [3] presented a spatial timevarying model of a subgrade-track-vehicle coupling system for dynamic analysis of subgrade. In the spatial model, the dynamic equation of the coupling system is founded with the energy theory. Under the continued harmonic irregularity, dynamic analyses were performed and used as the verification of the model. Galvín and Domínguez [4, 5] established a three-dimensional model for the analysis of train-induced vibrations. The model can represent local soil conditions and discontinuities such as underpasses. They compared the numerical results at several points near the track with experimental results from certification testing of the highspeed train line between Córdoba and Málaga [6].

Most analyses and calculation methods developed so far have addressed track subgrade vibrations induced by railway traffic; knowledge on the dynamic behaviors of track subgrade while trains are in service is rather limited in the literature. Some researchers have studied such effects based 

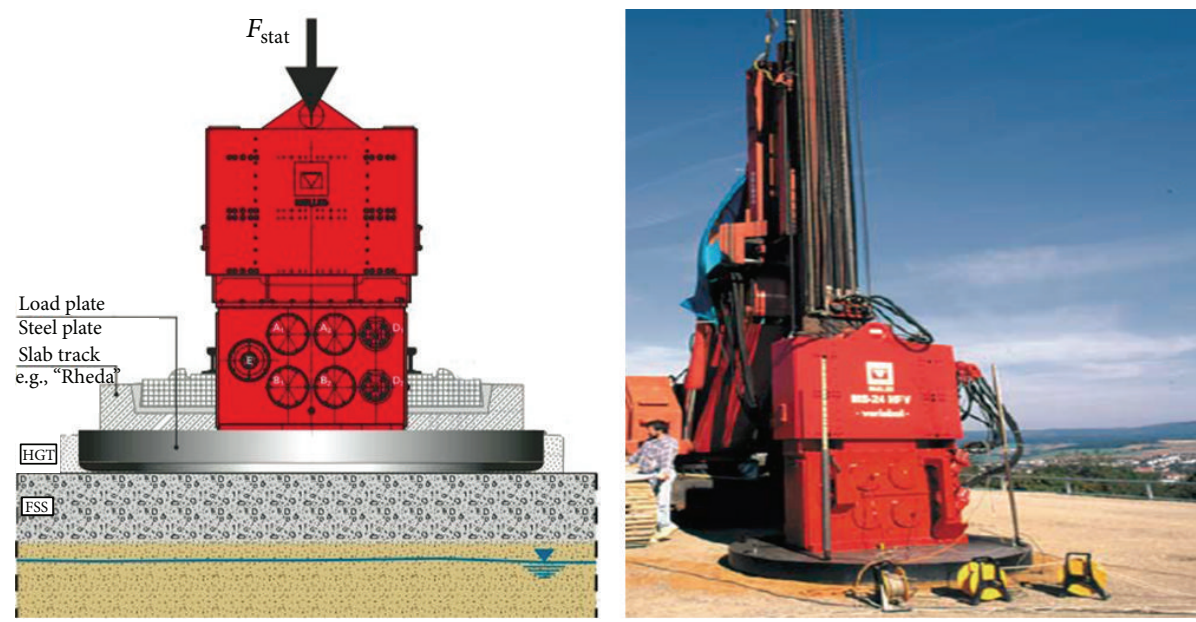

FIGURE 1: Deutsche Bahn AG dynamic stability test system.

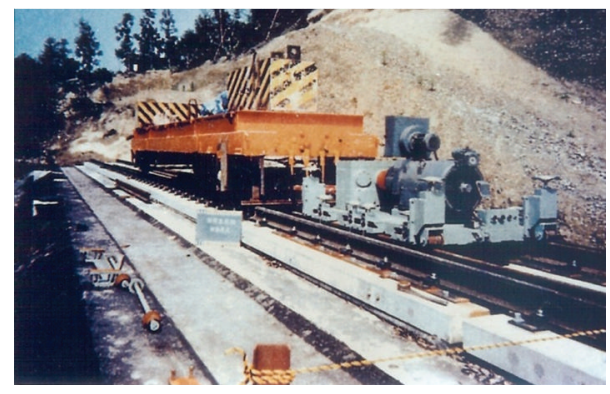

FIGURE 2: Platform of the repeated impact test conducted by Japan Railway's Railway Technical Research Institute.

on precommercial service testing, full-scale model tests, and in situ forced vibration tests. In 1995, Deutsche Bahn AG developed dynamic stability test system with an adjustable frequency range of $5-45 \mathrm{~Hz}$, as shown in Figure 1. Several experiments were conducted on railway networks in Germany and Netherlands using the equipment [7]. Japan Railway's Railway Technical Research Institute (JR) conducted a repeated impact test of track subgrade with an excitation force range of 9.8-98.0 kN under a fixed frequency of $7 \mathrm{~Hz}$, as shown in Figure 2, and performed several experiments to analyze the dynamic characteristics of ballastless track subgrade $[8,9]$. China Academy of Railway Sciences developed a dynamic vibration test system with maximum excitation frequency of $30 \mathrm{~Hz}$ and analyzed vibration characteristics of a bridge-subgrade transition section of a high-speed railway using in situ dynamic load experiments conducted by the dynamic vibration test system [10]. Yang and Zhou [11] studied the engineering characteristics of high and low subgrades of the Chinese He-Ning high-speed railway under simulative dynamic loads using cyclic loading equipment (the SBZ 60) with a maximum excitation force of $300 \mathrm{kN}$ and a frequency range of $9-30 \mathrm{~Hz}$, as shown in Figure 3. Wang et al. [12] conducted several in situ cyclic load experiments to analyze dynamic performance of red mudstone subgrade of ballasted

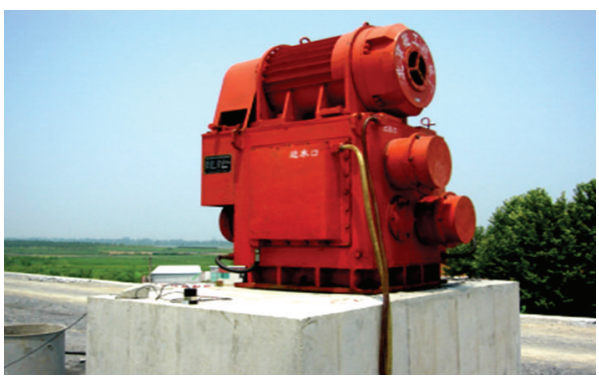

Figure 3: The SBZ 60 cyclic loading equipment.

track on the Dazhou-Chengdu railway line under different cyclic loads with and without the influence of rainfall.

Note that previous research mainly focused on the dynamic performance of subgrade supported by composite foundation or replacement ground. Limited studies concerned the influence of foundation stiffness on the vibration behaviors of the track slab-subgrade- foundation interaction. More specifically, the variation in dynamic behaviors with railway traffic and its impact on total life cycle of the subgrade structures and associated resonance-like phenomenon are yet to be investigated.

The outline of this paper is as follows. First, the pileplank-supported low subgrade of ballastless track is introduced. In that subgrade, the subgrade bed comprises coarse particles, which is located between the ballastless track and the pile-plank structure. The subgrade structure resembles a sandwich, with the ballastless track on the top and the pile-plank structure on the bottom and coarse particles in the center. Second, we describe the method of investigating the vibration characteristics of the pile-plank-supported low subgrade of the ballastless track on a high-speed railway to confirm safe operation. The method included two in situ experiments. The first experiment analyzed the vibrations of the pile-plank-supported low subgrade using frequency scanning prior to train operation. The second analyzed the 


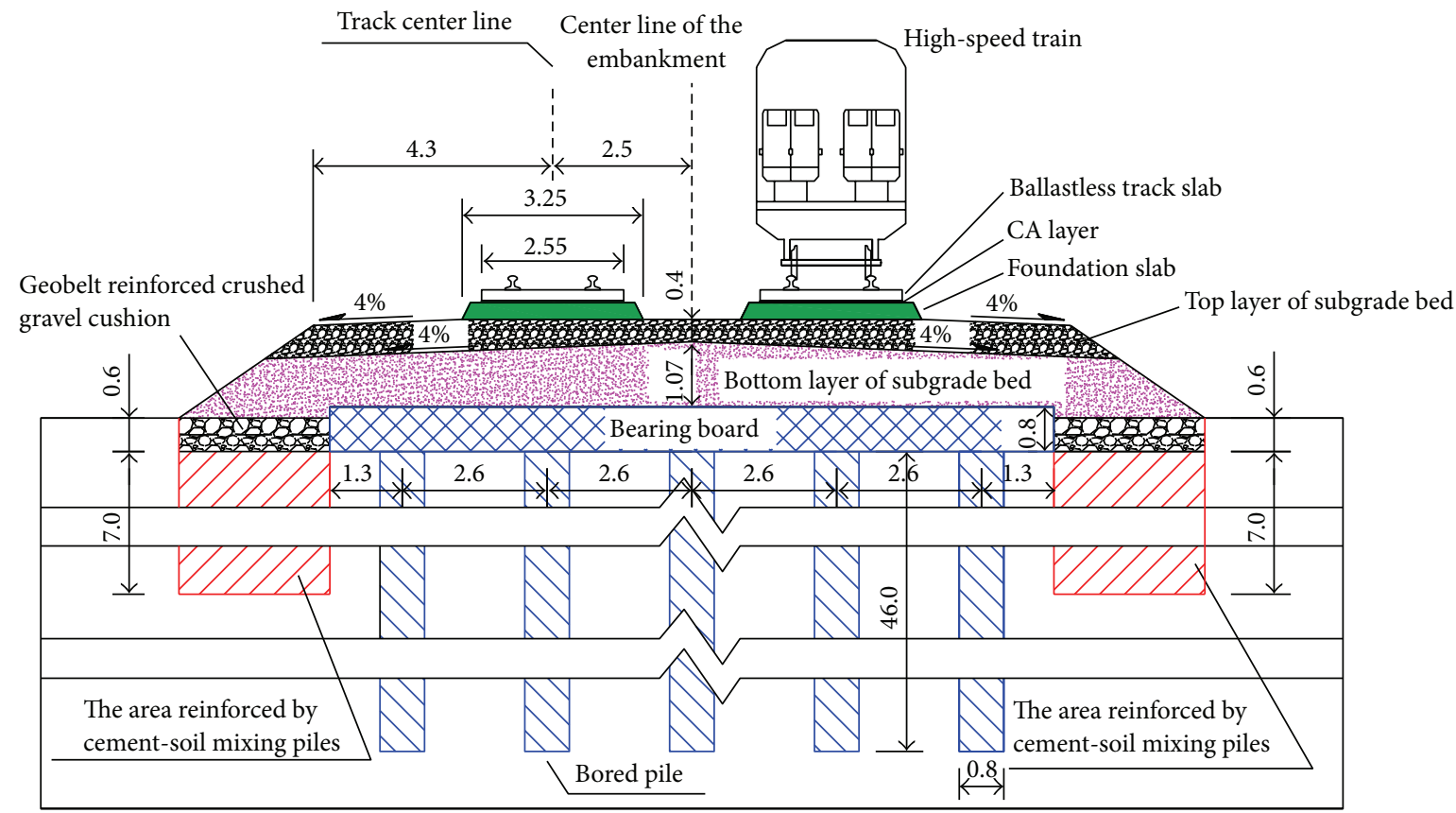

FIGURE 4: Geometry of the coarse particle sandwich structure of low subgrade.

dynamic performance of the subgrade during operation via application of simulated high-speed train dynamic loads on the foundation slab of the ballastless track.

\section{Pile-Plank-Supported Low Subgrade}

Pile-plank structures are widely used to reduce the subgrade settlement of ballastless track built in soft ground (e.g., on the Wuhan-Guangzhou, Beijing-Shanghai, and ShanghaiHangzhou high-speed railways and other lines). A typical pile-plank structure for a rail track comprises the ballastless track structure, a subgrade bed interlayer, and the pileplanks. When the subgrade height is less than the thickness of the subgrade bed, the subgrade bed is located between the ballastless track structure and the embedded pile-plank structure. In this paper, this system is called a pile-planksupported low subgrade of ballastless track and is shown in Figure 4.

The subgrade bed is formed by a top layer filled with graded broken stone and a bottom layer filled with coarse particle soil, the stiffness of which is much smaller than the pileplank structure bearing plank and the track slab, and forms a weak interlayer. The pile-plank-supported low subgrade of ballastless track can produce coupling action against each structure layer under high-speed train dynamic loads. The systemic coupling vibration effect increases the complexity of the stress state for the pile-plank-supported low subgrade of ballastless track, which is a problem not encountered by the low subgrade supported by other composite foundation strengthening technologies.

In this paper, the vibration characteristics and dynamic stability of pile-plank-supported low subgrade are studied using simulated high-speed train dynamic loads at the construction site shown in Figure 4.
The pile-plank structure comprises piles and bearing plank. At the study site, three spans compose one unit. The lengths of mid-span, side span, and cantilever are $8.0 \mathrm{~m}$, $7.0 \mathrm{~m}$, and $2.5 \mathrm{~m}$, respectively. Pile diameter and length are $0.8 \mathrm{~m}$ and $46.0 \mathrm{~m}$, respectively. Bearing plank width and thickness are $13.0 \mathrm{~m}$ and $0.8 \mathrm{~m}$, respectively. The subgrade bed that is filled directly on the bearing plank is divided into a top layer and bottom layer, as described above. The top layer thickness is $0.40 \mathrm{~m}$, and that of the bottom layer is $1.07 \mathrm{~m}$. It is essential that foundation coefficient $k_{30}$ is greater than $150 \mathrm{MPa} / \mathrm{m}$ and dynamic deformation modulus $E_{v d}$ is greater than $40 \mathrm{MPa}$ for the coarse particle soil compaction quality of the bottom layer. The top layer requires that foundation coefficient $k_{30}$ is greater than $190 \mathrm{MPa} / \mathrm{m}$ and dynamic deformation modulus $E_{v d}$ is greater than $55 \mathrm{MPa}$. After the subgrade bed is constructed, the ballastless track structure is laid on the surface of the subgrade bed top layer. Foundation slab expansion joints $(0.02 \mathrm{~m}$ wide) are set at $20 \mathrm{~m}$ intervals along the longitudinal route.

\section{Field Vibration Experimental Scheme}

After subgrade filling, a reinforced concrete slab $(2.22 \mathrm{~m}$ wide) was laid on the right line of the test section to simulate the ballastless track foundation slab, as shown in Figure 5(a). The in situ loading experiments were conducted on the right line for the mid-span and cantilever end of the pile-plank structure. The test section position is shown in Figure 6(a). The loading test comprises frequency sweeping and cyclic loading experiments.

A dynamic test system (DTS-1) used for simulating highspeed train dynamic load was placed on the reinforced concrete slab and connected by anchor screw, as shown in Figure 5(b). The frequency sweeping experiments were 


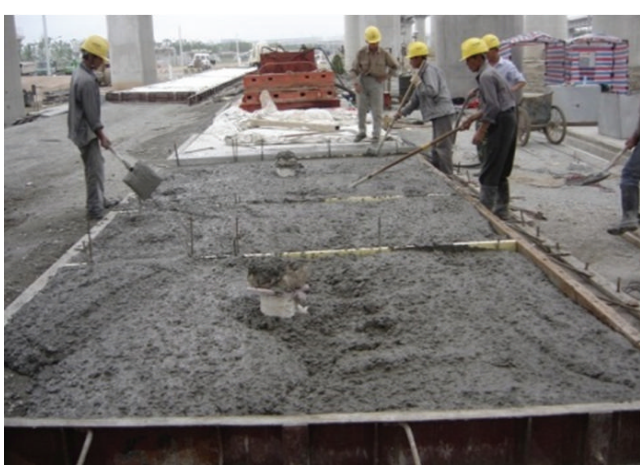

(a)

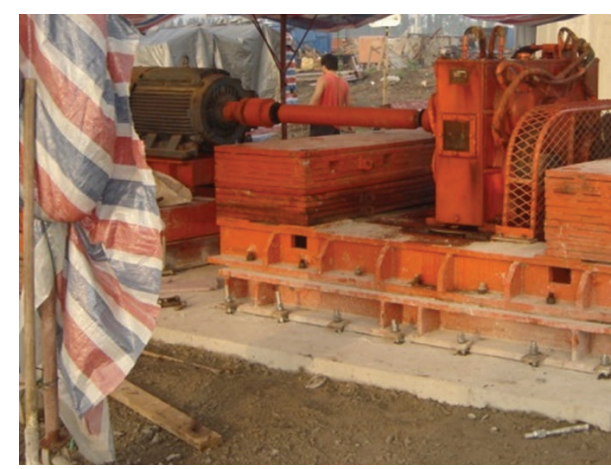

(b)

FIGURE 5: Field vibration experiment.

TABLE 1: Loading indices of frequency sweeping test.

\begin{tabular}{lcc}
\hline $\begin{array}{l}\text { Vibration exciter } \\
\text { weight }(\mathrm{kN})\end{array}$ & $\begin{array}{c}\text { Vibration } \\
\text { frequency }(\mathrm{Hz})\end{array}$ & $\begin{array}{c}\text { Maximum excitation } \\
\text { force }(\mathrm{kN})\end{array}$ \\
\hline 5 & 2.58 \\
7 & 5.06 \\
9 & 8.36 \\
11 & 12.48 \\
134.22 & 13 & 17.43 \\
15 & 23.21 \\
17 & 29.81 \\
19 & 37.23 \\
21 & 45.48 \\
23 & 54.56 \\
25 & 64.46 \\
\hline
\end{tabular}

TABLE 2: Loading indices of cyclic loading test.

\begin{tabular}{lccc}
\hline $\begin{array}{l}\text { Vibration } \\
\text { exciter weight } \\
(\mathrm{kN})\end{array}$ & $\begin{array}{c}\text { Vibration } \\
\text { frequency }(\mathrm{Hz})\end{array}$ & $\begin{array}{l}\text { Maximum } \\
\text { excitation } \\
\text { force }(\mathrm{kN})\end{array}$ & $\begin{array}{c}\text { Excitation } \\
\text { number of } \\
\text { cycles }\left(\times 10^{6}\right)\end{array}$ \\
\hline 134.22 & 20 & 41.25 & 2.0 \\
\hline
\end{tabular}

conducted on each loading test section followed by cyclic loading experiments. Loading parameters of the experiments are summarized in Tables 1 and 2, respectively.

3.1. Vibration Equipment. The dynamic loading test system (DTS-1) developed by Professor Su Qian of Southwest Jiaotong University was used for in situ frequency sweeping and cyclic loading experiments. The system mainly comprises a vibration exciter, transmission system, cooling system, and electrical control system. It can simulate high-speed train dynamic loads with a frequency range of $5-50 \mathrm{~Hz}$ and a maximum excitation force $340 \mathrm{kN}$, as shown in Figure 7.

The system uses the biaxial inertia vibration principle. The two output shafts of the vibration exciter rotate in the same speed oppositely and output biaxial centrifugal force. The inertial forces synthesized by biaxial centrifugal force produced in the horizontal and vertical direction are $0 \mathrm{kN}$ and the excitation force system needed, respectively. The excitation force varies by sine rule when the system is running at the same frequency. The maximum value of the excitation force can be obtained as follows:

$$
F_{\max }=m_{0} e(2 \pi f)^{2},
$$

where $m_{0}$ is the total quality of two off-center components $(\mathrm{kg}) ; e$ is eccentricity of off-center components $(\mathrm{m})$; and $f$ is rotating frequency of the shaft and represents vibration frequency $(\mathrm{Hz})$.

The excitation force is not the dynamic load applied on the subgrade surface, but the disturbing force of the vibration exciter, including vibrating table and activity counter weight. Based on the Winkler-Voigt model, a freedom vibration mode of single degree is established for the in situ dynamic loading test system, as shown in Figure $8 . K$ represents stiffness and $C$ is damping. The subgrade dynamic stress induced by the vibration exciter is mainly codetermined by the counter weight and excitation force value of vibration exciter and the subgrade stiffness and structure form. The subgrade dynamic stress experiment required can be obtained by debugging the total quality of two off-center components under condition of the maximum value of the excitation force less than vibration exciter weight, when the vibration frequency, counter weight of vibration exciter, and subgrade site are fixed.

3.2. Loading Parameters and Procedure. The time-history curve of the dynamic stress for the subgrade surface of ballastless track can be obtained by the in situ dynamic test at the speed of $350 \mathrm{~km} / \mathrm{h}$. Then through Fourier transformation for the time-history curve, the frequency response curve can be obtained, which indicates the real axle load acting on the subgrade of ballastless track. As shown in Figure 8, the frequency of the dynamic stress for the subgrade surface is between 0 and $15.51 \mathrm{~Hz}$. The field test of the NurembergIngolstadt railway in Germany also showed load frequency on ballastless track subgrade that was less than $15.0 \mathrm{~Hz}$ [13].

The frequency corresponding to the dynamic stress amplitude peak of the subgrade surface is the main frequency of subgrade surface dynamic stress when the train passes. 


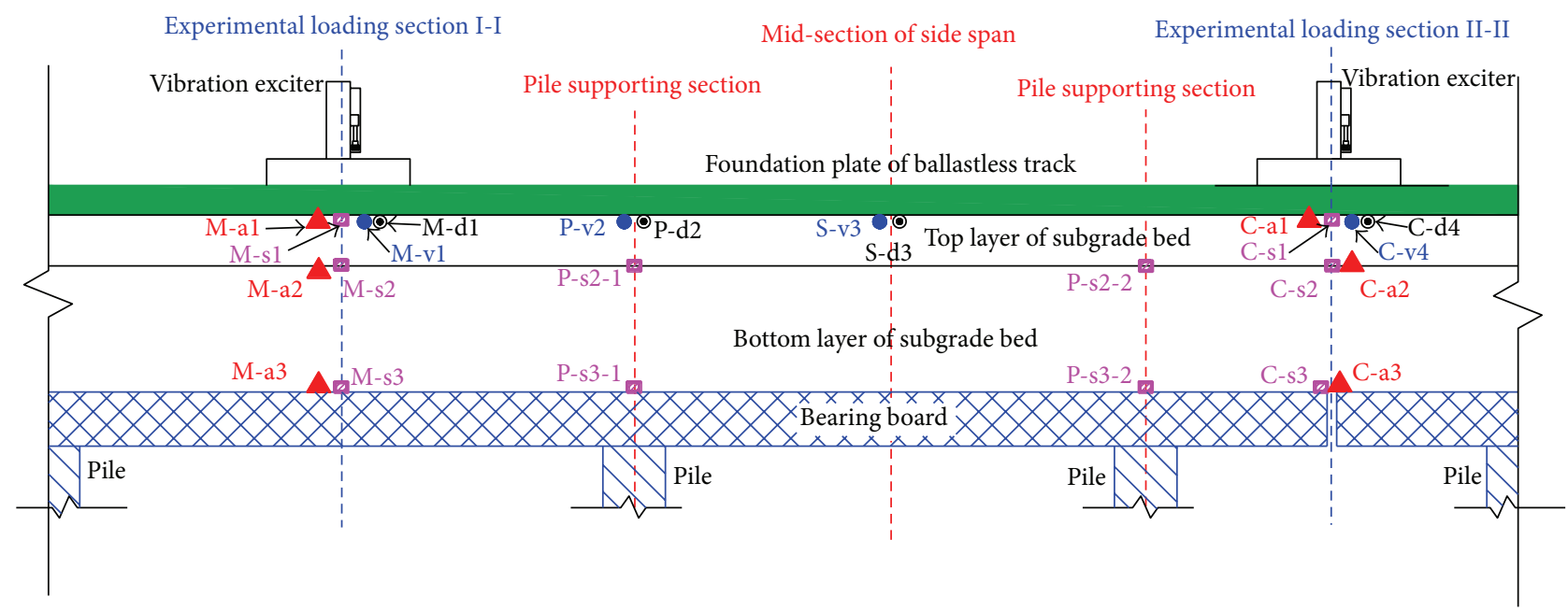

(a) Longitudinal section of track center line

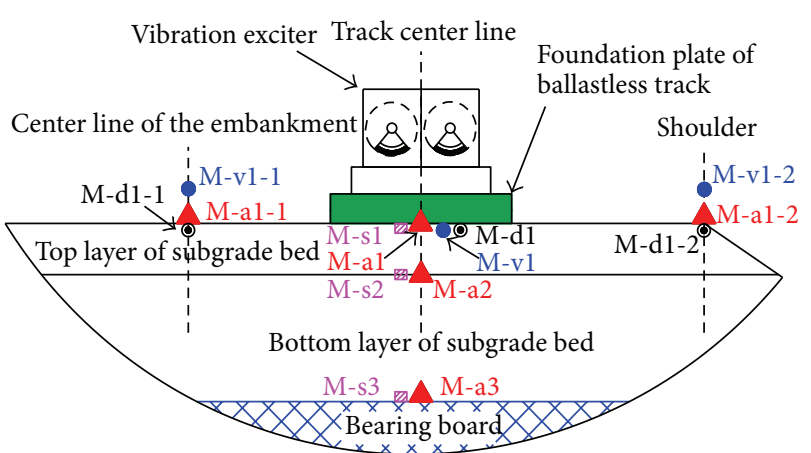

Test site and instrumentation:
$\triangle$ Accelerometer
Z Dynamic soil pressure sensor
Velocimeter
(-) Dynamic displacement sensor

(b) Cross section of mid-section in the middle span

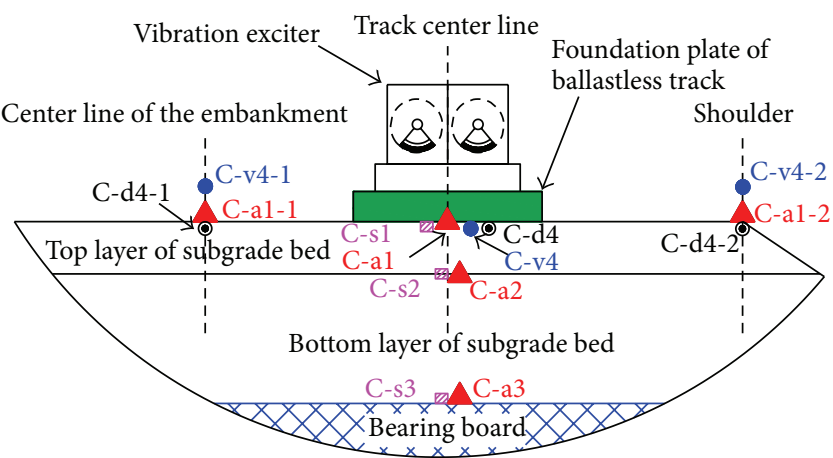

Test site and instrumentation:
Accelerometer $\square$ Dynamic soil pressure sensor
Velocimeter

(c) Cross section of cantilever end

FIgURE 6: Test site and instrumentation.

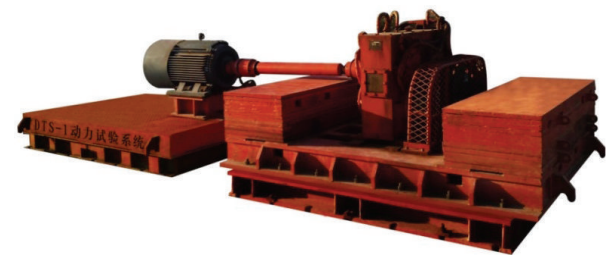

FIgURE 7: The structure of the vibrating table.

With reference to Figure 9, a mathematical relationship is found as follows:

$$
f_{1} \approx \frac{f_{2}}{2} \approx \frac{f_{3}}{3} \approx \frac{f_{4}}{4} .
$$

The frequency of subgrade surface dynamic stress induced by train load is calculated by the following formula:

$$
f=\frac{v}{3.6 \times L},
$$

where $f$ is the dynamic load frequency $(\mathrm{Hz}) ; v$ is train speed $(\mathrm{km} / \mathrm{h})$; and $L$ is the perturbation wavelength.

The perturbation wavelength is a set of lengths, including the carriage length, distance between bogie centers, and wheelbase length. The frequency induced by train load is $f=$ $f_{1}=3.89 \mathrm{~Hz}$, calculated by formula (3) under the condition of the perturbation wavelength taken as train carriages, when the carriage length is $25.0 \mathrm{~m}$ and train speed is $350 \mathrm{~km} / \mathrm{h}$, which indicates that the frequency corresponding to the dynamic stress amplitude peak of the subgrade surface is coincident with the main loading frequency. The main frequency of train load on subgrade vibration is coincident with the fundamental frequency induced by train carriage length, so the train carriage length is the basic perturbation wavelength determining the dominant frequency of load on subgrade. Therefore, in the numerical calculation and indoor and outdoor tests, the frequency of dynamic load acting on subgrade load is determined on the basis of train speed and carriage length. The test is for the design speed of $450 \mathrm{~km} / \mathrm{h}$; the frequency induced by train load is $f=f_{1}=5.00 \mathrm{~Hz}$, 


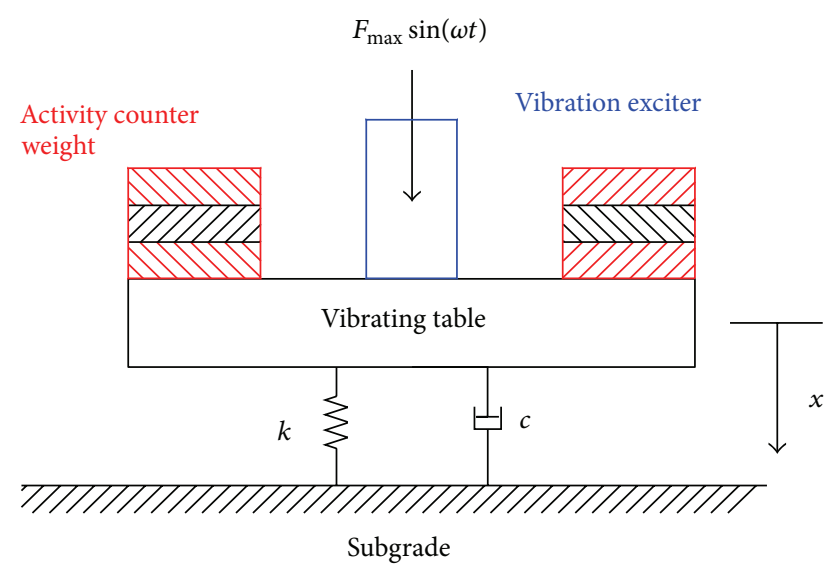

FIGURE 8: Freedom vibration mode of single degree for the in situ dynamic loading test system.

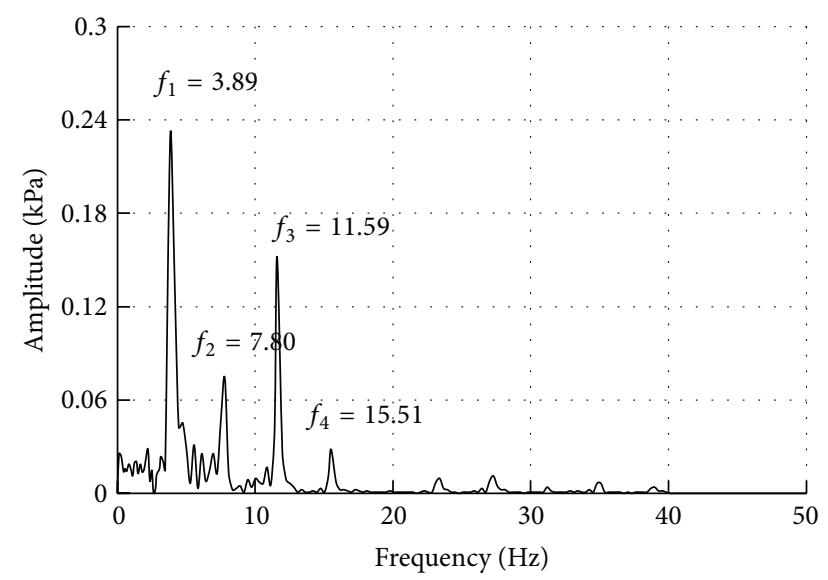

FIGURE 9: The frequency spectrum curve of dynamic soil pressure at the surface of subgrade $(v=350 \mathrm{~km} / \mathrm{h})$.

calculated by formula (3). Correspondingly, $f_{4}=4 f_{1}=$ $20.00 \mathrm{~Hz}$. In view of the above, the frequency of cyclic loading experiments is $20 \mathrm{~Hz}$. In order to achieve vibration characteristics under more frequencies, the excitation frequency range of frequency sweeping experiments is approximately $5-25 \mathrm{~Hz}$.

The counterweight of the vibration exciter was $134.22 \mathrm{kN}$ in both the frequency sweeping and cyclic loading experiments, and the eccentricity and total mass of off-center components were also the same $(36.28 \mathrm{~kg}$ and $144 \mathrm{~mm}$, resp.). In the frequency sweeping experiments, the output excitation force of the vibration exciter increased from $5.16 \mathrm{kN}$ to $128.91 \mathrm{kN}$ with the frequency increase from $5 \mathrm{~Hz}$ to $25 \mathrm{~Hz}$. The output excitation force for the frequency sweeping experiments is a variable frequency disturbance force. Consequently, the natural vibration frequency of the pileplank-supported low subgrade is analyzed by the relationship between vibration frequency and unit amplitude obtained by dividing the vertical vibration displacement of embankment by excitation force.

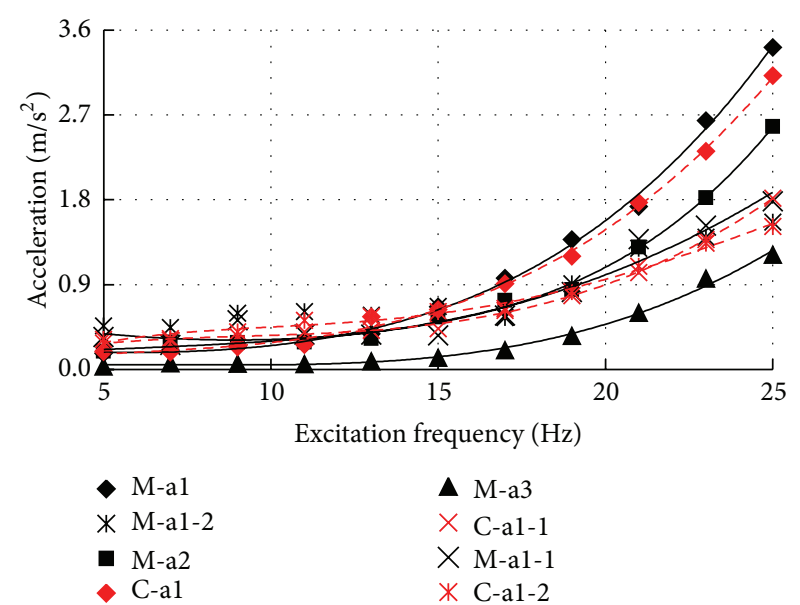

FIGURE 10: Vertical acceleration on the soil versus vibration exciter input frequency.

The output excitation force of the vibration exciter is $41.25 \mathrm{kN}$ when the frequency of the cyclic loading experiment is $20 \mathrm{~Hz}$. Based on verification tests performed before the cyclic loading experiments, the dynamic soil pressure of the subgrade surface of the mid-span and cantilever end of the pile-plank structure is approximately $18 \mathrm{kPa}$, which corresponds to the results of the numerical calculation and field test $[3,14,15]$ shown in Table 3 . Therefore, we can conclude that the dynamic soil pressure in the cyclic loading experiments is consistent with that induced by trains.

The frequency sweeping experiments were conducted with different excitation frequency, and the loading time at each frequency was 180 seconds. The data acquisition time was $10 \mathrm{~s}$ from the start of the second minute at each loading frequency. The excitation time of the cyclic loading experiment was 2 million for simulating wheel load numbers during one year.

3.3. Testing Content and Method. The dynamic soil pressure, displacement, vibration velocity, and acceleration for the subgrade bed were tested in both the frequency sweeping and cyclic loading experiments, besides cumulative settlement of the embankment under cyclic loading condition. Therefore, the corresponding test sensors were buried during the construction process, as shown in Figure 6. The dynamic data was gathered by a dynamic acquisition system during field tests.

\section{Experimental Results}

4.1. Induced Vibration Characteristics due to Frequency Sweeping Test. The low subgrade vibration response of the midspan and cantilever end of the pile-plank structure is showed in Figures 10 and 11. There was an increase of loading frequency from $5 \mathrm{~Hz}$ to $25 \mathrm{~Hz}$ in the frequency sweeping experiments.

From Figures 10 and 11, the dynamic soil pressure, vertical displacement, vibration velocity, and acceleration of the pile-plank-supported low subgrade in the mid-span and 

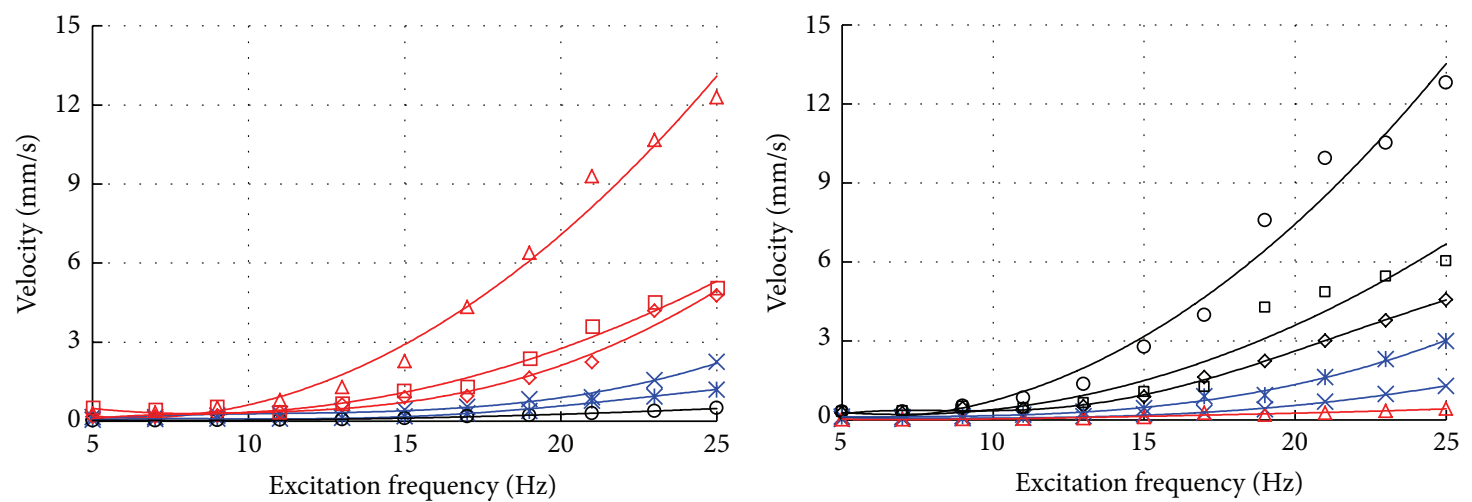
$\triangle \mathrm{C}$-v4
$\times$ S-v3
* P-v2
O M-v1
$\diamond \mathrm{C}-\mathrm{v} 4-1$
ㄷ C-v4-2

(a)

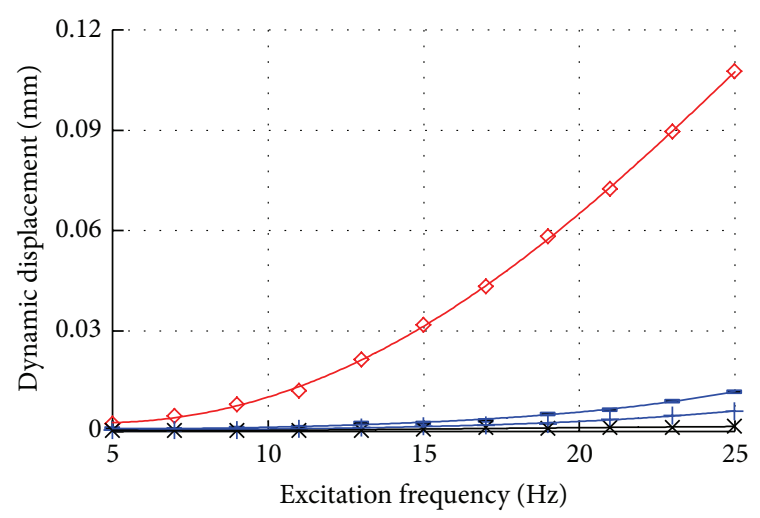

$\diamond \mathrm{C}-\mathrm{d} 4$

$-\mathrm{S}-\mathrm{d} 3$

$+\mathrm{p}-\mathrm{d} 2$

$\times$ M-d1

(c)

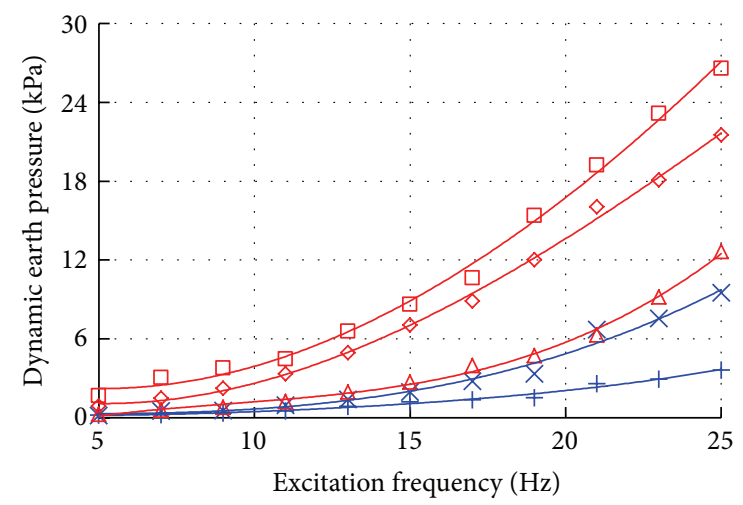

$\begin{array}{ll}+ \text { P-s2-2 } & \diamond \mathrm{C}-\mathrm{s} 2 \\ \times \text { P-s3-2 } & \Delta \text { C-s3 } \\ \square \text { C-s1 } & \end{array}$

(e)
O M-v1
* P-v2
$\triangle \mathrm{C}-\mathrm{v} 4$
$\times$ S-v3
$\diamond \mathrm{M}-\mathrm{v} 1-1$
ㅁ M-v1-2

(b)

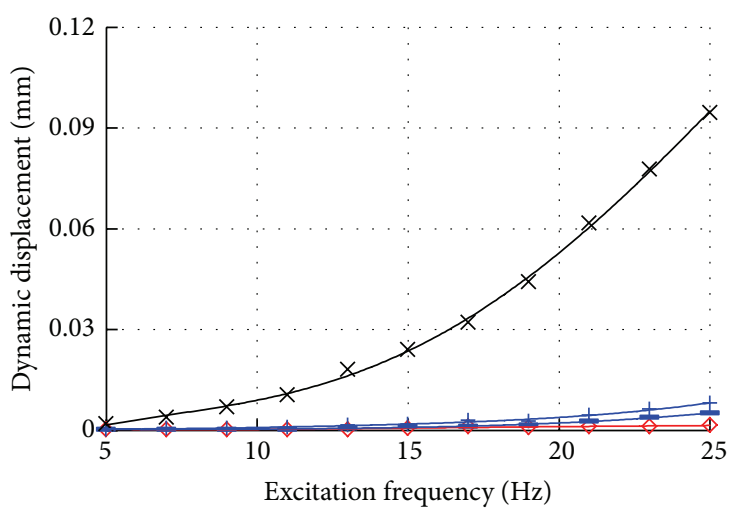

$\diamond \mathrm{C}-\mathrm{d} 4$

$+\mathrm{p}-\mathrm{d} 2$

- S-d3

$\times$ M-d1

(d)

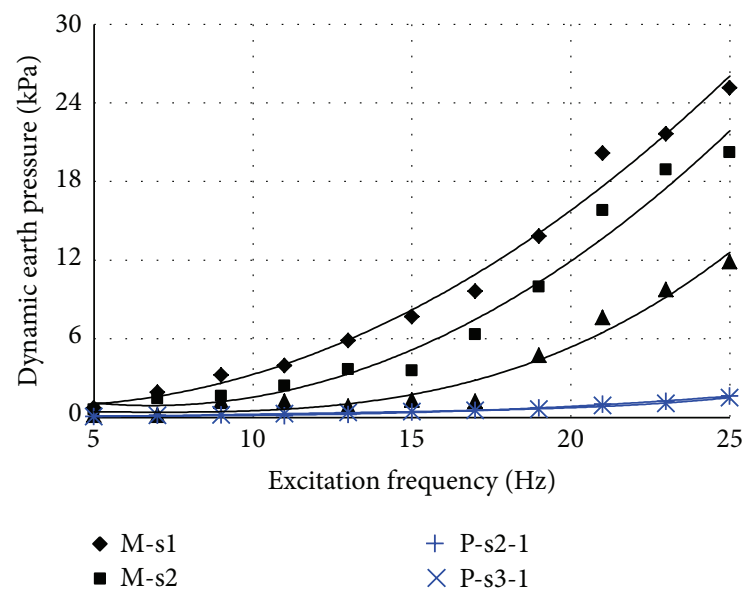

(f)

FIGURE 11: Vertical velocity, dynamic displacement, and dynamic soil pressure of subgrade versus vibration frequency. (a), (c), and (e) show vibration force acting on section II-II. (b), (d), and (f) show vibration force acting on section I-I. 
TABLE 3: Dynamic soil stress measured at subgrade bed surface.

\begin{tabular}{|c|c|c|c|c|}
\hline Railway line & Vehicle model & Track type & $\begin{array}{c}\text { Train speed } \\
(\mathrm{km} / \mathrm{h})\end{array}$ & $\begin{array}{c}\text { Dynamic soil pressure } \\
(\mathrm{kPa})\end{array}$ \\
\hline $\begin{array}{l}\text { Germany Cologne-Rhine new } \\
\text { line [13] }\end{array}$ & ICE-3 & & $140 \sim 326$ & $15.0 \sim 20.0$ \\
\hline $\begin{array}{l}\text { Germany Nuremberg-Ingolstadt } \\
\text { line [13] }\end{array}$ & ICE-3 & Ballastless slab track & $220 \sim 297$ & $13.0 \sim 20.0$ \\
\hline $\begin{array}{l}\text { China Wuhan-Guangzhou line } \\
\text { [18] }\end{array}$ & CRH-2 & & $280 \sim 350$ & $14.6 \sim 16.9$ \\
\hline Full-scale model tests [19] & $\mathrm{CRH}-3$ & & $5 \sim 360$ & $18.2 \sim 19.6$ \\
\hline
\end{tabular}

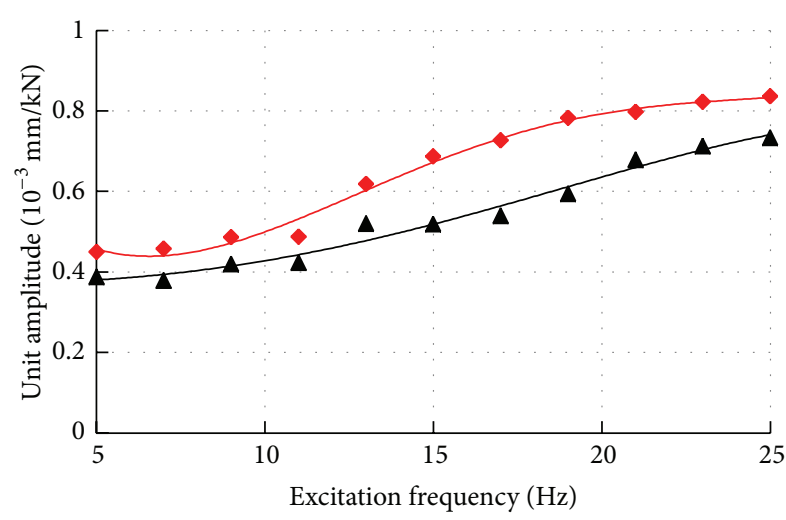

- Section I-I

- Section II-II

FIGURE 12: Unit amplitude of the subgrade surface versus vibration frequency.

cantilever end of the pile-plank structure increase exponentially with excitation force frequency (from $5 \mathrm{~Hz}$ to $25 \mathrm{~Hz}$ ), but the peaks in vibration response parameters do not appear.

Vibrations of the low subgrade are almost the same when the same frequency excitation force outputted by the vibration exciter is applied on the low subgrade surface of the mid-span and cantilever end of the pile-plank structure. Although excitation force frequency reaches $25.0 \mathrm{~Hz}$ (maximum excitation force $=64.46 \mathrm{kN}$ ), the maximum dynamic soil pressure of the low subgrade surface of the mid-span of the pile-plank structure is $25.148 \mathrm{kPa}$ and that of the cantilever end is $26.586 \mathrm{kPa}$. The maximum vertical vibration acceleration in the two locations is $0.349 \mathrm{~g}$ and $0.318 \mathrm{~g}$, the maximum vertical vibration velocity is $12.820 \mathrm{~mm} / \mathrm{s}$ and $13.423 \mathrm{~mm} / \mathrm{s}$, and the maximum dynamic displacement is $0.095 \mathrm{~mm}$ and $0.108 \mathrm{~mm}$. These results indicate that the pileplank-supported low subgrade of ballastless track has smooth stiffness along the longitudinal subgrade.

Figure 12 shows the unit amplitude versus excitation frequency. Figure 12 shows that the unit amplitude of the low subgrade surface of the mid-span and cantilever end of the pile-plank structure slowly increases when excitation frequency is less than $11.0 \mathrm{~Hz}$ and increases significantly later. The peak of unit amplitude does not appear in the range of approximately $5.0-25.0 \mathrm{~Hz}$. This suggests that the resonancelike phenomenon does not occur on the pile-plank-supported low subgrade under excitation frequency ranges of $5-25 \mathrm{~Hz}$.

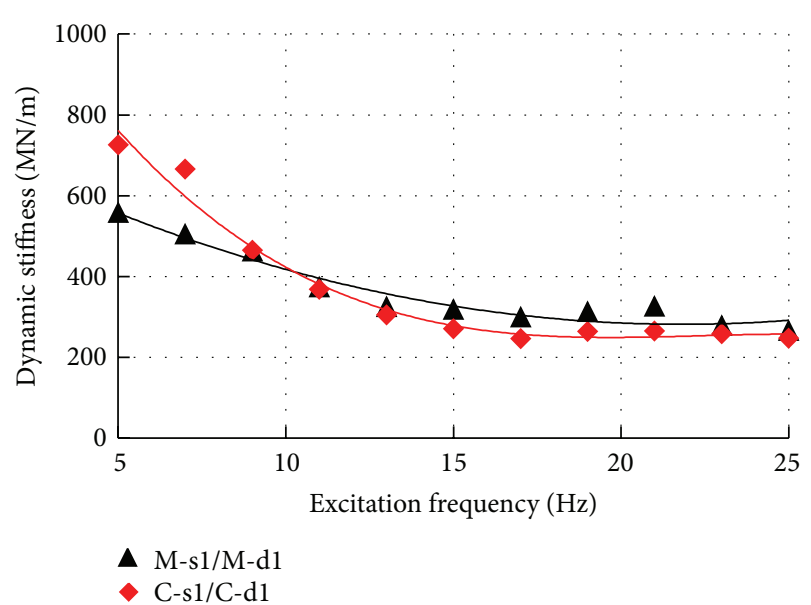

FIGURE 13: Dynamic stiffness of the subgrade versus vibration frequency.

The resonance frequency range of low subgrade structure of ordinary ballasted track and ballastless track is $15.0-17.0 \mathrm{~Hz}$ $[1,16,17]$ under dynamic train load. When excitation force frequency from $5 \mathrm{~Hz}$ to $25 \mathrm{~Hz}$ was imposed, the resonancelike phenomenon did not occur on the pile-plank-supported low subgrade of ballastless track on this site. Analysis suggests that the pile-plank structure limits the subgrade mass being vibrated and changes the transfer mechanism of subgrade dynamic load, making the pile-plank-supported low subgrade vibrations different from other subgrades of ordinary ballasted and ballastless track.

The dynamic stiffness of the subgrade reflects its ability to resist dynamic deformation under train running. Larger dynamic stiffness is associated with stability of the track structure and driving comfort. The dynamic stiffness $K_{d}$ can be calculated as follows:

$$
K_{d}=\frac{\sigma_{d \max }}{S_{d}}
$$

where $\sigma_{d \max }$ is the peak value of subgrade surface dynamic stress and $S_{d}$ is subgrade surface dynamic displacement corresponding to the peak value of subgrade surface dynamic stress. $\sigma_{d \max }$ and $S_{d}$ are measured from the sensors buried in the subgrade surface under the vibration exciter.

Figure 13 shows dynamic stiffness $K_{d}$ versus excitation frequency at the study site. The dynamic stiffness of the low 


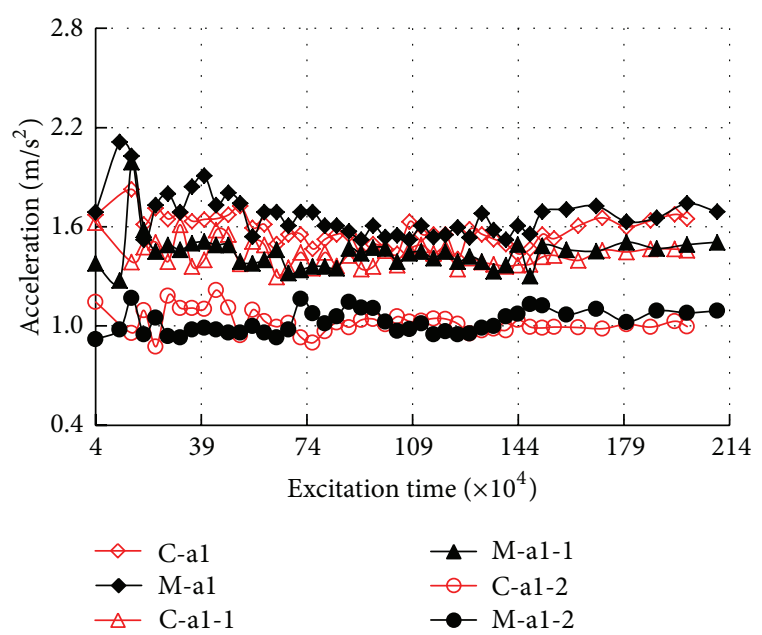

(a)

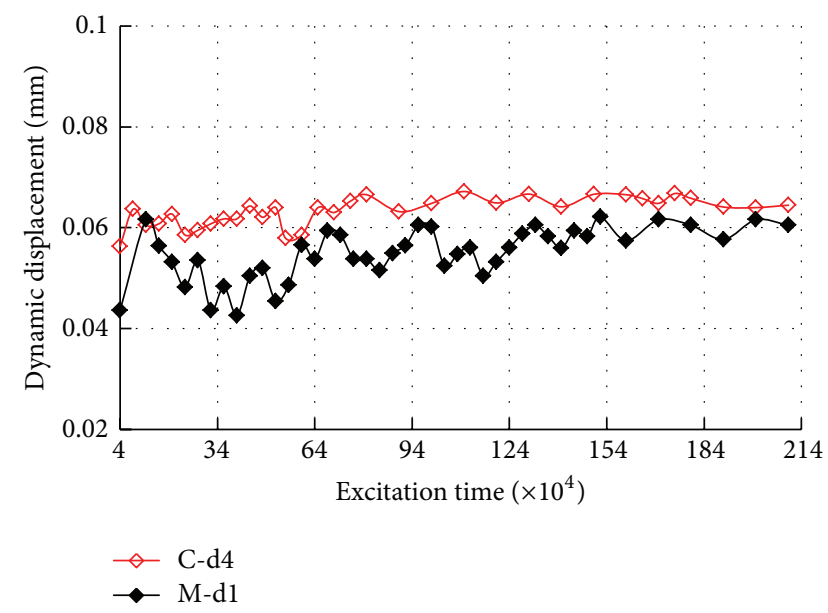

(c)

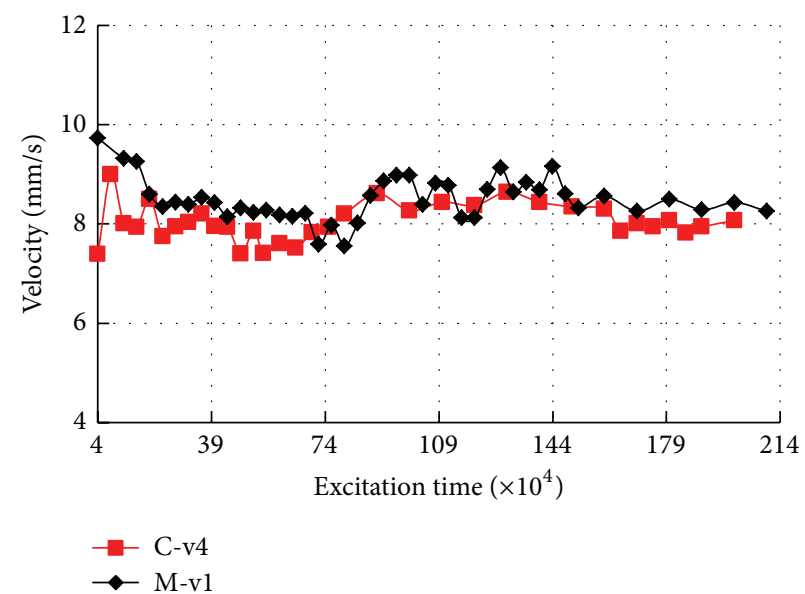

(b)

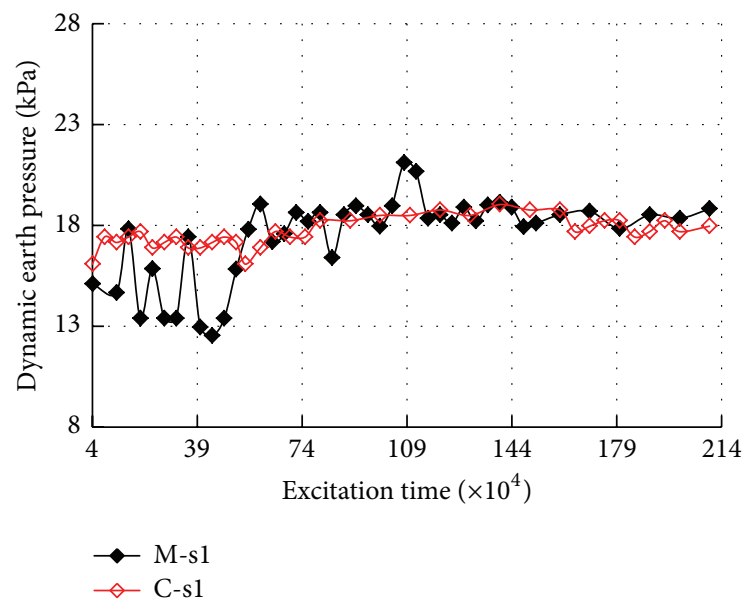

(d)

FIGURE 14: Vibration response of the low subgrade versus vibration times: vertical acceleration (a), vertical velocity (b), dynamic displacement (c), and dynamic soil pressure (d) of the low subgrade versus vibration times.

subgrade in both sections decreased slightly at first with the increase in excitation frequency and then stabilized when excitation frequency reached more than $17.0 \mathrm{~Hz}$. The ultimate value was $245-310 \mathrm{MPa} / \mathrm{m}$. These results indicate that the pile-plank-supported low subgrade of ballastless track can efficiently control the effect of speed increases on dynamic stiffness of subgrade, so as to ensure driving comfort and safety.

\subsection{Dynamic Performance under Cyclic Loading. Figure 14} shows dynamic soil pressure, vertical displacement, vibration velocity, and acceleration of the low subgrade supported by the pile-plank structure. These values are compared with excitation time of the cyclic loading experiment.

Dynamic soil pressure, vertical displacement, vibration velocity, and acceleration of the low subgrade at the midspan and cantilever end of the pile-plank structure fluctuate at the preliminary stage of loading and tend to stablity when the excitation time is more than 1.0 million. The vertical displacement, vibration velocity, and acceleration of the low subgrade in both sections are approximately the same, which indicates that the pile-plank-supported low subgrade has smooth stiffness along the longitudinal subgrade under the condition of the same thickness of subgrade bed.

Figures 14(b) and 14(c) show that the vertical vibration velocity of the low subgrade surface at the loading center at the mid-span and cantilever end of the pile-plank structure is $8.25-9.16 \mathrm{~m} / \mathrm{s}$ and $7.82-8.64 \mathrm{~m} / \mathrm{s}$, respectively. Dynamic displacement is less than $0.067 \mathrm{~mm}$ when the vibration responses of the pile-plank-supported low subgrade approach stability. The vertical vibration velocity and displacement of the low subgrade decrease rapidly along the longitudinal subgrade and are close to zero when transmitted to the cross section of the pile bearing position, as shown in Figure 15. Thus, the vibration of the low subgrade occurs in the loading span of the pile-plank structure.

Variations of vertical vibration acceleration and dynamic soil pressure of the low subgrade under the center of the 


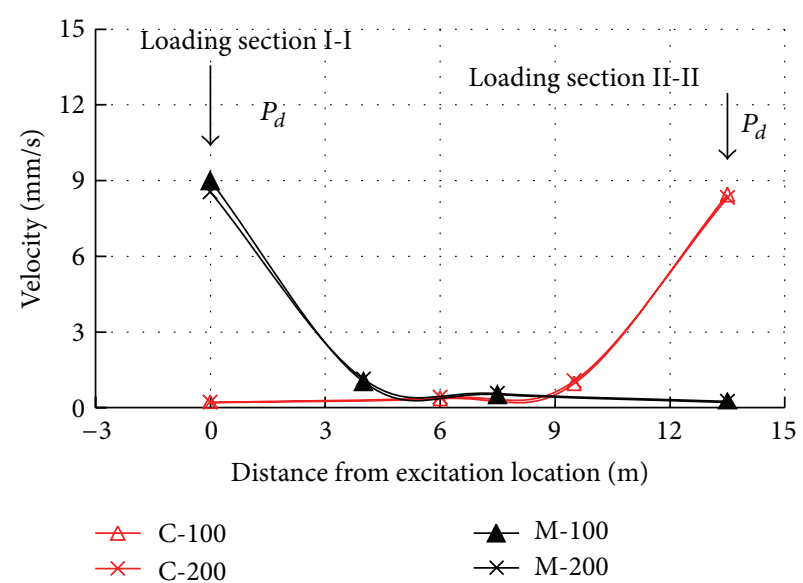

(a)

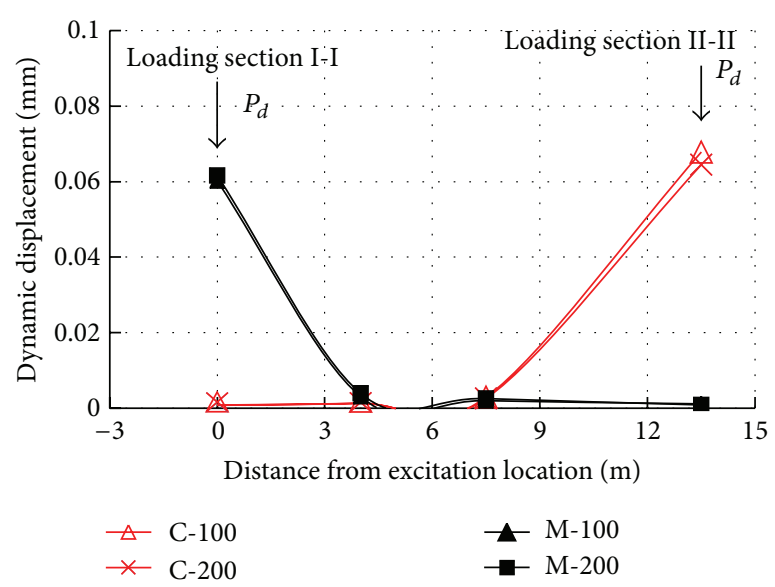

(b)

FIGURE 15: Distribution of vertical velocity (a) and dynamic displacement (b) of the low subgrade beneath the foundation plate along the longitudinal subgrade.

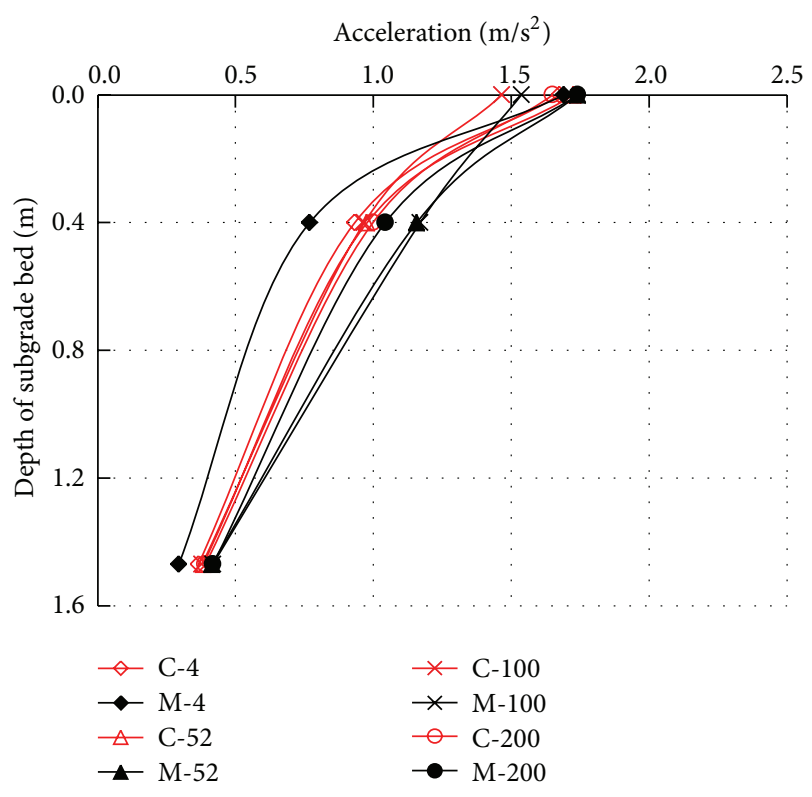

(a)

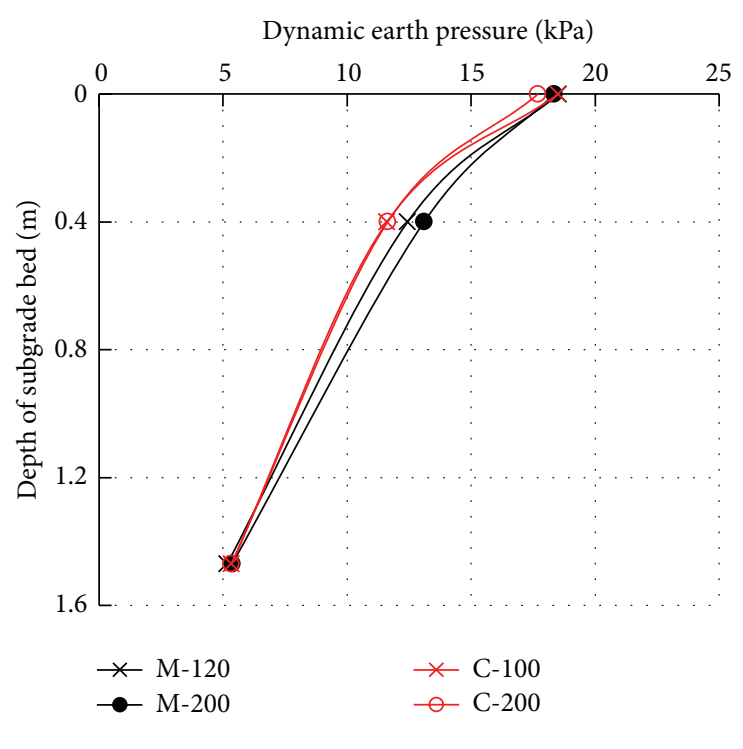

(b)

FIGURE 16: Distribution of vertical acceleration (a) and dynamic soil pressure (b) of the low subgrade under vibration loading along depth.

vibration exciter are shown in Figure 16, under different excitation times. Figure 16(a) shows that the vertical vibration acceleration of the low subgrade at the mid-span and that at cantilever end of the pile-plank structure that is transmitted from the subgrade surface to the bottom surface of the subgrade bed top layer decay on average by $38.0 \%$ and $40.3 \%$, respectively (at the two locations). They decay on average by $76.9 \%$ and $76.6 \%$ in transmitting to the bottom surface of the subgrade bed bottom layer. Note that, with the increase of subgrade depth, the vibration acceleration of the low subgrade rapidly decreases because of the geometrical effect of the subgrade structure and the damping effect of the subgrade bed. The above results show that the subgrade bed filled with graded broken stone for a top layer and coarse particle soils for a bottom layer has a good vibration buffer effect.

With the increase of excitation time, the low subgrade surface dynamic soil pressure at the mid-span and cantilever end gradually approach stability after the cyclic loading of 0.8 million and 1.16 million, respectively. The stable values are in the range of $17.84-19.14 \mathrm{kPa}$ and $17.43-19.04 \mathrm{kPa}$, respectively, which indicates that the dynamic soil pressure of the low subgrade surface in both sections is approximately the same under the same excitation conditions. As shown in Figure 16(b), the dynamic soil pressure of the low subgrade decreases rapidly along the depth of subgrade. After the 


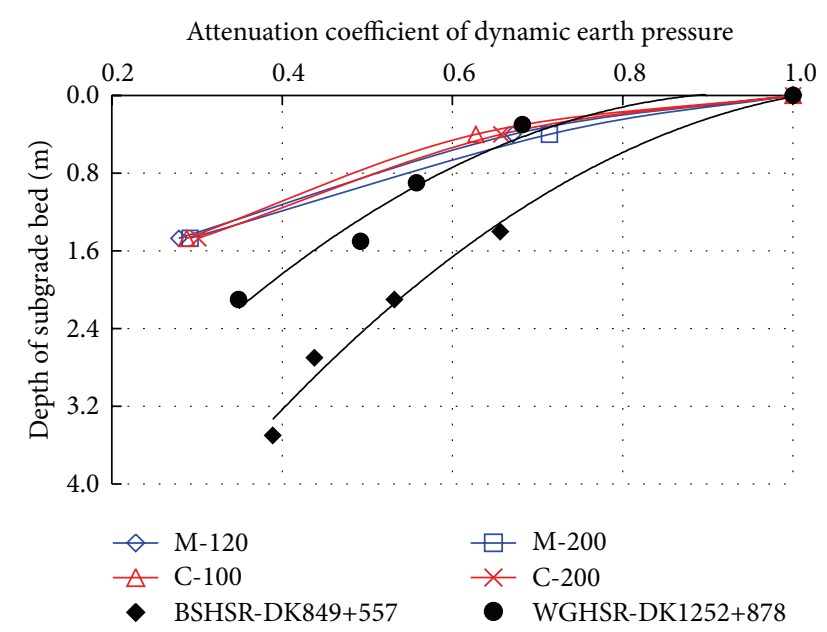

Figure 17: Dynamic soil pressure of subgrade along depth of subgrade.

excitation times of 1.2 million and 2 million, the dynamic soil pressure transmitted from the subgrade surface to the bottom surface of the subgrade bed top layer and to the bottom surface of the subgrade bed bottom layer decays at least by $28.6 \%$ and $70.8 \%$, respectively, at the mid-span section. At the cantilever end, the decay percentage is at least $34.2 \%$ and $69.8 \%$, respectively, after the excitation times of 1.0 million and 2.0 million. The in situ measured results of the dynamic soil pressure of the ordinary subgrade structure on the Wuhan-Guangzhou (WGHSR) and Beijing-Shanghai (BSHSR) high-speed railways at the speed of $300 \mathrm{~km} / \mathrm{h}$ and the experimental results in this paper are contrasted in Figure 17.

Figure 17 shows that the attenuation coefficient of dynamic soil pressure of pile-plank-supported low subgrade along subgrade depth decreases faster than that of ordinary subgrade supported by composite foundation on the BeijingShanghai and Wuhan-Guangzhou high-speed railways. This indicates that the pile-plank structure changes the transfer rules of dynamic soil stress of the low subgrade, and the dynamic soil stress is transmitted to the pile-plank structure rapidly, improving the whole dynamic stability of the subgrade.

Figure 18 shows the curves of the low subgrade cumulative settlement at the mid-span and cantilever end of the pile-plank structure alongside vibration times. The low subgrade cumulative settlement in both sections increases rapidly at the preliminary stage of loading and then tends to be stable after excitation times reach 0.9 and 1.0 million, respectively. After the excitation time reaches 2 million, the maximum cumulative settlements of the low subgrade surface in both sections are $0.36 \mathrm{~mm}$ and $0.31 \mathrm{~mm}$, respectively. This illustrates that settlement and uneven settlement of pileplank-supported low subgrade meet design requirements for ballastless track subgrade on high-speed railways.

Dynamic stiffness of the low subgrade surface at the mid-span and cantilever end of the pile-plank structure under different excitation times can be calculated by formula (4). Figure 19 shows the variation of dynamic stiffness of

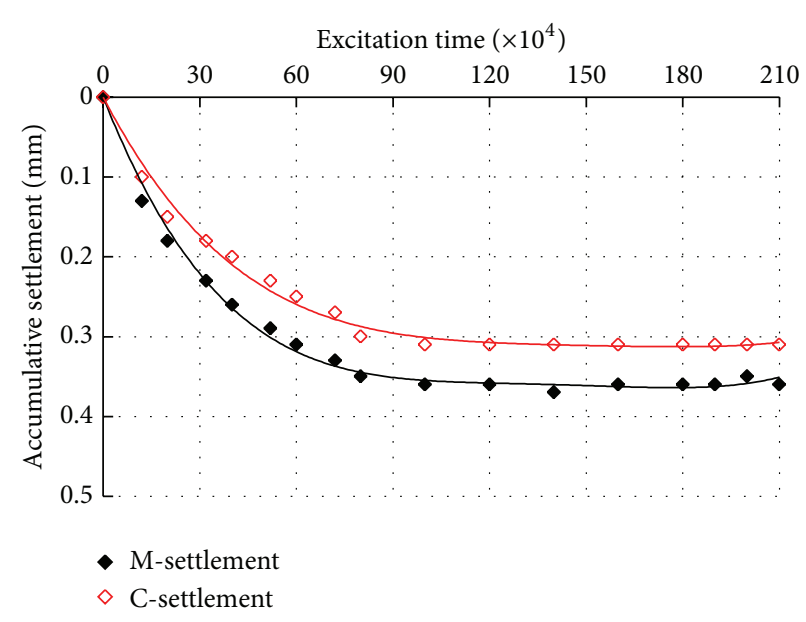

FIGURE 18: Cumulative settlement of subgrade in different stages.

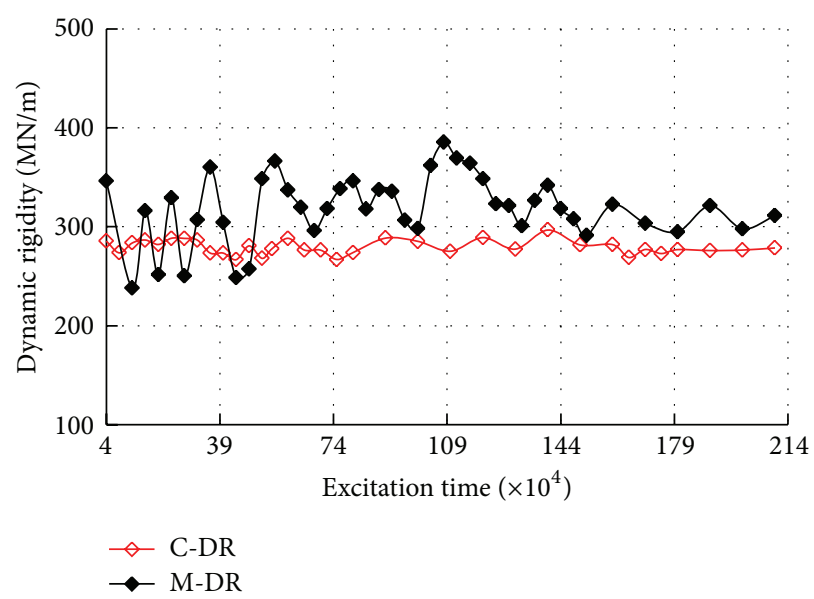

FIGURE 19: Dynamic rigidity of subgrade versus vibration times.

the low subgrade surface with the excitation times. The dynamic stiffness of the low subgrade surface in both sections fluctuates at first and then tends to be stable as excitation time increases. Under excitation force of $41.25 \mathrm{kN}$ (vibration frequency $20 \mathrm{~Hz}$ ), the dynamic stiffness of the subgrade surface at the mid-span and cantilever end of the pile-plank structure is in the range of $291.16-322.55 \mathrm{MPa} / \mathrm{m}$ and $272.92-$ $296.71 \mathrm{MPa} / \mathrm{m}$, respectively. After this, it stabilizes. The subgrade surface dynamic stiffness distribution of pile-planksupported low subgrade is uniform along the longitudinal subgrade. The results show that the flexible subgrade bed weakens the effect that any stiffness differences of the pileplank structure along the longitudinal subgrade have on the subgrade surface stiffness, ensuring the uniform distribution of dynamic stiffness of ballastless track in the longitudinal direction.

\section{Conclusions}

This paper presents an experimental study to investigate vibration characteristics and long-term performance of pileplank-supported low subgrade of ballastless track under 
excitation loads. This study was conducted based on typical conditions in field for the construction of ballastless track subgrade over soft ground. A typical pile-plank structure for a rail track comprises the ballastless track structure, a subgrade bed interlayer, and the pile-planks.

In situ frequency sweeping and cyclic loading experiments are used in this study. The results of frequency sweeping experiments show that the vibrations of the low subgrade at the mid-span and cantilever end of the pile-plank structure are almost the same, and the resonance-like phenomenon does not occur on the low subgrade under excitation with frequency ranging from 5 to $25 \mathrm{~Hz}$. The dynamic stiffness of the subgrade surface in both sections gradually tends to stablity when the excitation frequency reaches $17 \mathrm{~Hz}$, and the ultimate stiffnesses are almost identical. These results indicate that the low subgrade has smooth stiffness along the longitudinal subgrade.

The results from cyclic loading experiments show that vibration responses of the pile-plank-supported low subgrade gradually tend to stablity after 1 million cycles of cyclic loading. The maximum subgrade surface settlement is less than $0.36 \mathrm{~mm}$ after 2 million cycles of cyclic loading. These results indicate that the pile-plank-supported low subgrade of ballastless track has favorable long-term dynamic stability.

\section{Conflict of Interests}

The authors declare that there is no conflict of interests regarding the publication of this paper.

\section{Acknowledgments}

The work described in this paper was supported by the National Natural Science Foundation of China (Grant no. 51378441), the Fundamental Research Funds for the Central Universities (Grant no. 2682014CX063), and the Program for New Century Excellent Talents in University (Grant no. NCET-12-0941).

\section{References}

[1] P.-N. Thach, H.-L. Liu, and G.-Q. Kong, "Vibration analysis of pile-supported embankments under high-speed train passage," Soil Dynamics and Earthquake Engineering, vol. 55, pp. 92-99, 2013.

[2] S. Li, Y. Lai, S. Zhang, Y. Yang, and W. Yu, "Dynamic responses of Qinghai-Tibet railway embankment subjected to train loading in different seasons," Soil Dynamics and Earthquake Engineering, vol. 32, no. 1, pp. 1-14, 2012.

[3] Q. Su and Y. Cai, "Spatial time-varying coupling model for dynamic analysis of high speed railway subgrade," Journal of Southwest Jiaotong University, vol. 36, no. 5, pp. 509-513, 2001.

[4] P. Galvín and J. Domínguez, "Analysis of ground motion due to moving surface loads induced by high-speed trains," Engineering Analysis with Boundary Elements, vol. 31, no. 11, pp. 931-941, 2007.

[5] P. Galvín and J. Domínguez, "High-speed train-induced ground motion and interaction with structures," Journal of Sound and Vibration, vol. 307, no. 3, pp. 755-777, 2007.
[6] P. Galvín and J. Domínguez, "Experimental and numerical analyses of vibrations induced by high-speed trains on the CórdobaMálaga line," Soil Dynamics and Earthquake Engineering, vol. 29, no. 4, pp. 641-657, 2009.

[7] T. Neidhart, "True-to-scale in-situ tests determining dynamic performance of soil works under high speed train loading," FH Regensburg-University Applied Science, 2001.

[8] T. Odaka, "Analyses on performance test of ballasted track on subgrade by guideway testing machine," Railway Technical Research Pre-report 183, 1985.

[9] M. Sunaga and Y. Chikama, "A study on adaptation of shirasu for railroad embankment," Railway Technical Research Prereport 38, 1987.

[10] W.-B. Ma, Z.-L. Han, and Z.-L. Zhu, "Vibration characteristics of high speed railway's bridge-subgrade transition section," Chinese Journal of Geotechnical Engineering, vol. 31, no. 1, pp. 124-128, 2009.

[11] Y.-P. Yang and S.-H. Zhou, "Analysis of vibration character of expansive soil embankments with different heights of He-Ning high-speed railway," Rock and Soil Mechanics, vol. 29, no. 5, pp. 1403-1406, 2008.

[12] Z.-M. Wang, G.-L. Jiang, Y.-X. Wei, and A.-H. Hu, "Experimental study on dynamic performance of red mudstone subgrade of Dazhou-Chengdu Railway under cyclic loads," Chinese Journal of Geotechnical Engineering, vol. 30, no. 12, pp. 1888-1893, 2008.

[13] Y.-F. Hu and N.-F. Li, Theory of Ballastless Track-Subgrade for High Speed Railway, China Railway Publishing House, Beijing, China, 2010.

[14] Y. Hu, "Long-term dynamic stability of subgrade underhigh speed railway line-from theory to practice," SCR-SG021, Obermeyer Planen + Beraten GmbH (OPB), Munich, Germany, 2008.

[15] L. Wentian and W. Yonghe, "Dynamic stress analysis of subgrade-bridge transition section of qinshen railway," Chinese Journal of Rock Mechanics and Engineering, vol. 23, no. 3, pp. 500-504, 2004.

[16] C. Madshus and A. M. Kaynia, "High-speed railway lines on soft ground: dynamic behaviour at critical train speed," Journal of Sound and Vibration, vol. 231, no. 3, pp. 689-701, 2000.

[17] X.-C. Bian, H.-G. Jiang, W.-F. Jin, J.-Q. Jiang, R.-P. Chen, and Y.-M. Chen, "Full-scale model tests on slab track-subgrade interaction and load transfer in track system," Chinese Journal of Geotechnical Engineering, vol. 34, no. 8, pp. 1488-1495, 2012.

[18] X.-H. Liu, G.-L. Yang, and L.-L. Wang, "Dynamic response testing and analysis on red-clay cutting bed under ballastless track of high-speed railway," Geotechnical Investigation \& Surveying, vol. 39, no. 8, pp. 12-18, 2011.

[19] H.-G. Jiang, X.-C. Bian, X. Xu, Y.-M. Chen, and J.-Q. Jiang, "Full-scale model tests on dynamic performances of ballastless high-speed railways under moving train loads," Chinese Journal of Geotechnical Engineering, vol. 36, no. 2, pp. 354-362, 2014. 

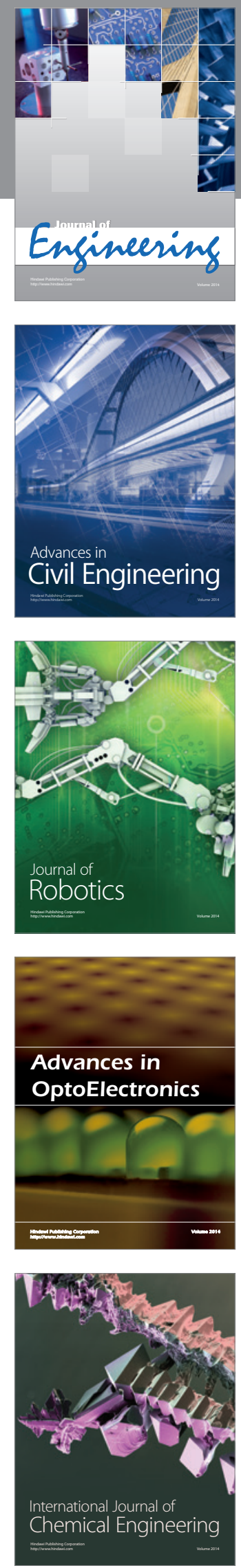

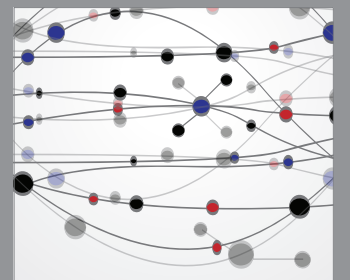

The Scientific World Journal
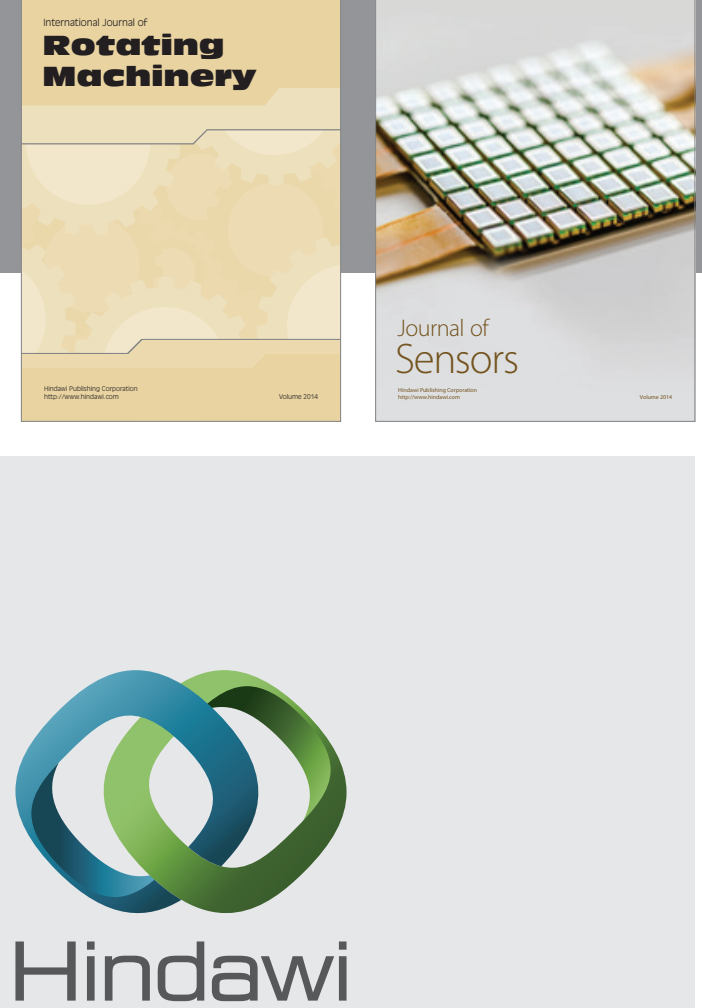

Submit your manuscripts at http://www.hindawi.com
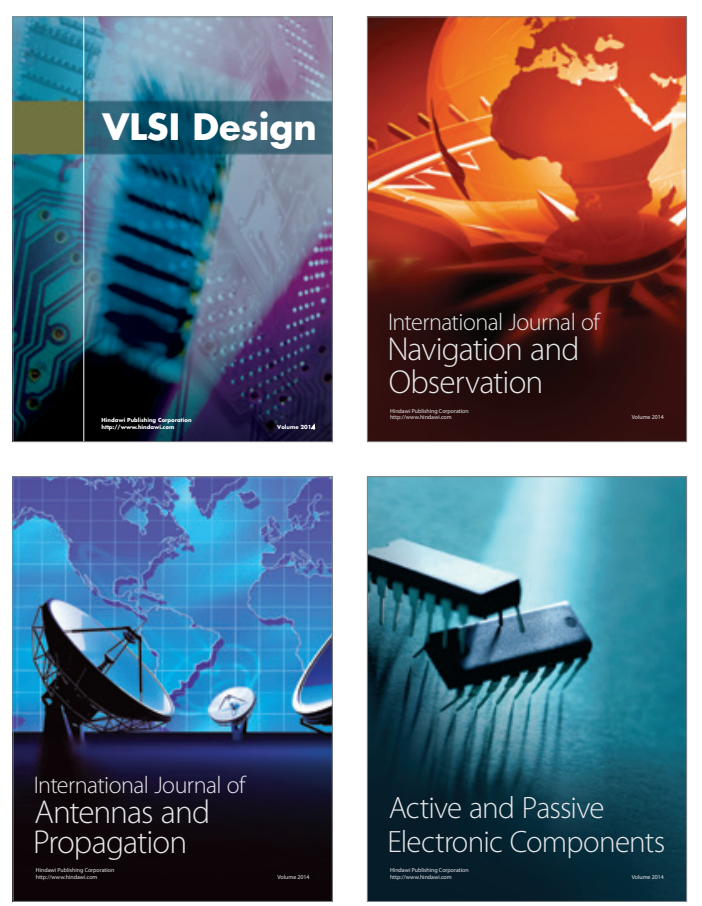
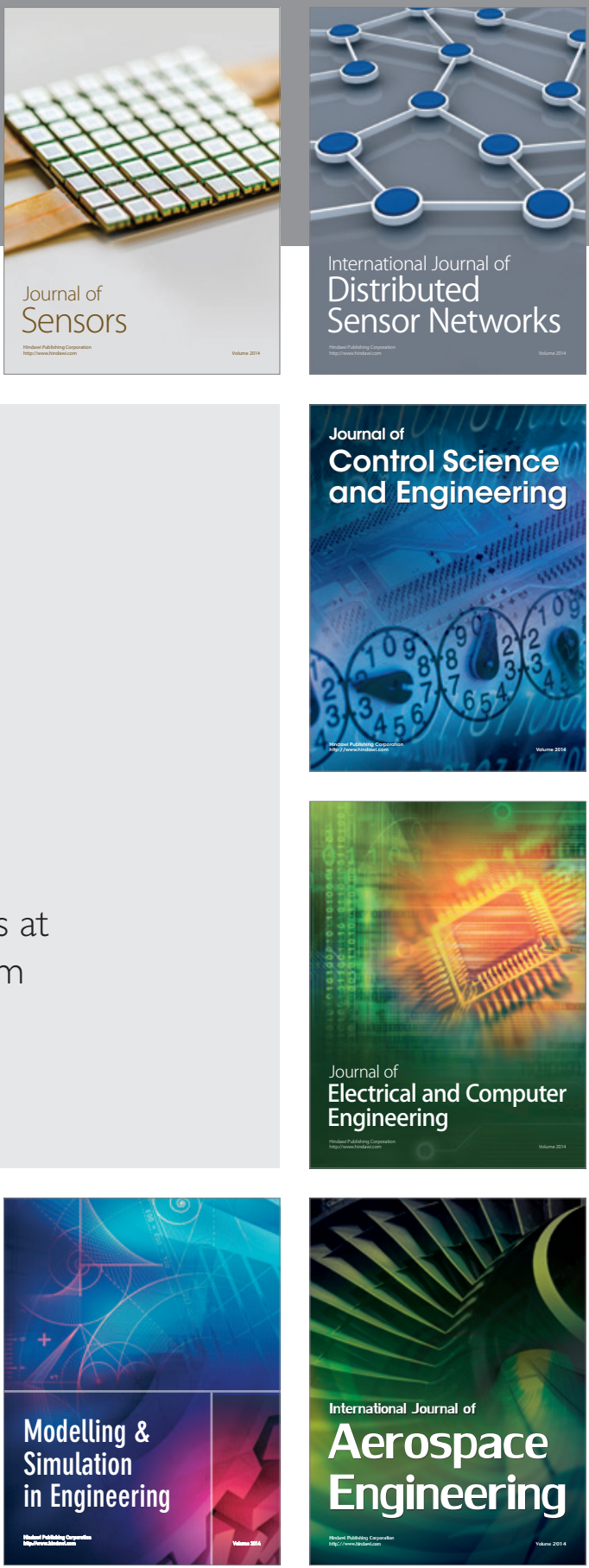

Journal of

Control Science

and Engineering
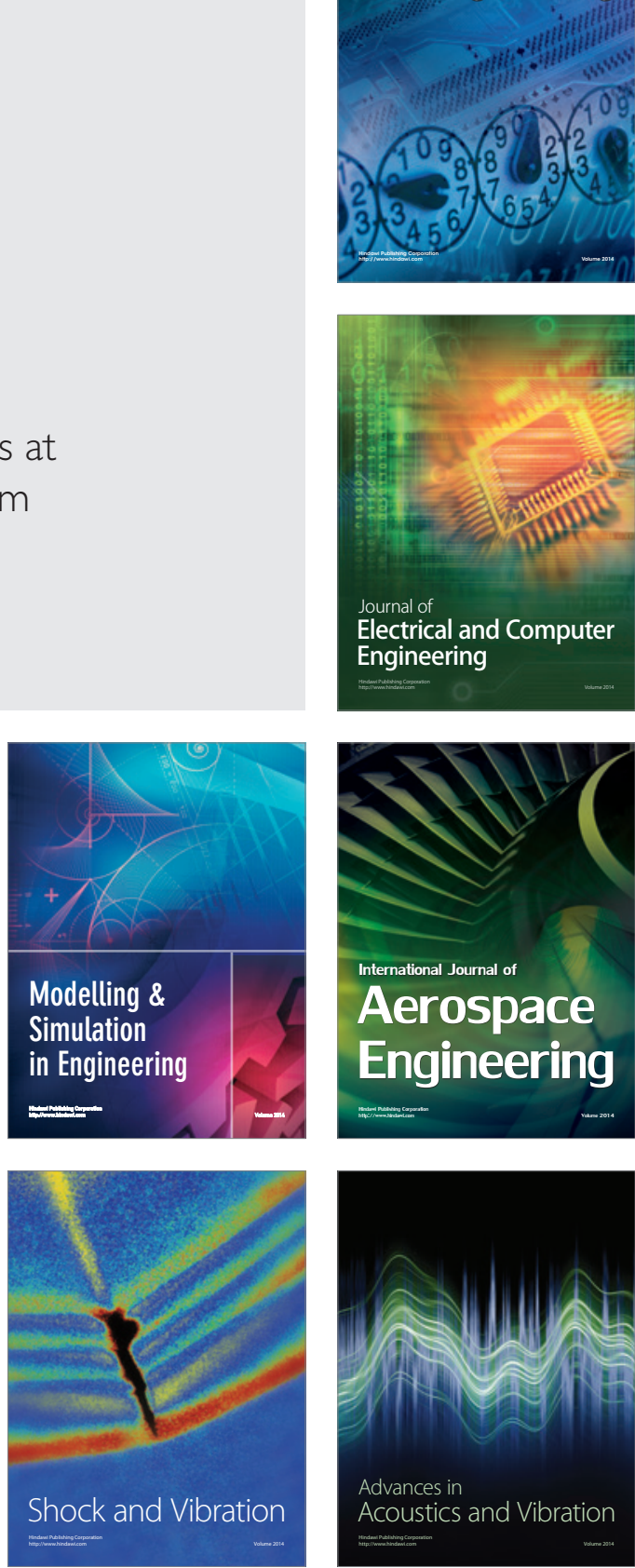